\title{
Lojistik Yönetiminin Dijital Dönüşümü: Akıllı Lojistik Üzerine Sistematik Literatür Haritalaması
}

\author{
Halil KARLI*, Mehmet TANYAŞ**
}

ÖZ

Tüm sektörlerin dijital dönüşümüyle birlikte ortaya çıkan "akıllı" kavramı teknolojiye dayalı çözümlerin önem kazanmasını sağlamıştır. Akıllı fabrikalarla birlikte kullanılan nesnelerin interneti, siber fiziksel sistemler, 3D yazıcılar vb. teknolojilerin hayatın farklı alanlarına dâhil edilmesiyle "akıllı şehirler", "akıllı binalar", "akıllı ulaşım", "akıllı enerji” gibi teknoloji odaklı yönetim süreçleri ortaya çıkmıştır. Akıllılık kavramı, tedarik zinciri ve lojistik alanında da kendini göstererek dijital dönüşümün bu alanlarda da ortaya çıkmasını sağlamıştır. Son yıllarda bu alana yönelik çalışmaların artmasına rağmen literatürün mevcut durumu ve yönelimler hakkında yeterli düzeyde bilgi bulunmamaktadır. Bu çalışmanın amacı akıllı lojistikle ilgili yapılan çalışmaların sistematik bir derlemesini sunmak ve literatürdeki boşlukları ortaya koyarak bu alanda çalışacak araştırmacılara katkı sağlamaktır. Çalışmada yöntem olarak sistematik haritalama kullanılmıştır. "Web of Science", "Scopus" ve "Dergipark" veri tabanları kullanılarak yapılan araştırmada 67 makale değerlendirilmiştir. İnceleme sonucunda akıllı lojistikle ilgili yapılan çalışmalara yönelik tanımlayıcı bulgular, akıllı lojistiğin getirdiği avantajlar, uygulamada karşılaşılan engeller ortaya konulmuştur.

Anahtar Kelimeler: Lojistik Yönetimi, Akıllı Lojistik, Dijital Dönüşüm, Lojistik 4.0, Endüstri 4.0

JEL Sinıflandırması: L91, M11

\section{Digital Transformation of Logistics Management: A Systematic Literature Mapping on Smart Logistics}

\begin{abstract}
The concept of "smart", which emerged with the digital transformation of all sectors, enabled technology based solutions to gain importance. Internet of things, cyber physical systems, 3D printers etc. technologies have become popular with digital transformation. By incorporating these technologies into different areas of life, technology-oriented management processes such as "smart cities", "smart buildings", "smart transportation" and "smart energy" have emerged. Smart concept has also shown itself in the field of supply chain and logistics, enabling digital transformation to occur in these areas as well. Despite the increasing studies in this area in recent years, there is not enough information about the current state of the literature and trends. The aim of this study is to present a systematic review of studies on smart logistics and to contribute to researchers who will work in this field by revealing the gaps in the literature. Systematic mapping was used as a method in the study. 67 articles were evaluated in the research using databases of "Web of Science", "Scopus" and "Dergipark". As a result of the review, descriptive findings, advantages brought by smart logistics, and obstacles encountered in practice were revealed.
\end{abstract}

Keywords: Logistics Management, Smart Logistics, Digital Transformation, Logistics 4.0, Industry 4.0

JEL Classification: L91, M11

Geliş Tarihi / Received: 12.04.2020 Kabul Tarihi / Accepted: 31.05 .2020

\footnotetext{
* Araş. Gör., Bartın Üniversitesi, İİB, Uluslararası Ticaret ve Lojistik Bölümü, karli.halil@yahoo.com, ORCID: 0000-0002-5366-9774

** Prof. Dr., Maltepe Üniversitesi, İşletme ve Yönetim Bilimleri Fakültesi, Uluslararasi Ticaret ve Lojistik Yönetimi Bölümü, mehmettanyas@gmail.com, ORCID: 0000-0001-8934-3787
} 


\section{GÍRIŞ}

Son yıllarda en popüler kelimelerin başında "akıllı" gelmektedir. Ak1llı telefonlar, akı1lı fabrikalar, akı1lı lojistik, akı1lı evler, akıllı kentler, ak1llı yollar gibi birçok konuda yoğun bir akılcılaşma girişimi bulunmaktadır. Bu akılcılaşma akımından payını lojistik yönetimi de almıştır. Lojistik yönetiminde akıllı sistemlerin kullanımı geleneksel lojistiğin eksik kalmasıyla birlikte önerilmeye başlanmasına rağmen 2011 yılında Hannover fuarında ortaya çıkan, Almanya'nın yeni oluşturduğu sanayi atılımı "endüstri 4.0" kavramıyla popülerlik kazanmıştır (Krykavskyy, Pokhylchenko, ve Hayvanovych, 2019: 275; Pan, 2012: 441). Endüstri 4.0 kavramı birçok ülke tarafından farklı isimlerle anılmaktadır. Bunlardan bazıları; ABD; "ileri üretim ortaklığı", İngiltere; "üretimin geleceği”, Avrupa Komisyonu; "fabrikaların geleceği”, Güney Kore; "üretim 3.0'da inovasyon" ve Çin; "Çin yapımı 2025" ( Liao, Deschamps, Loures, ve Ramos, 2017: 3610) şeklindedir. Ancak hem lojistik alanına öncülük etmesi hem de dördüncü sanayi devrimini çağrıştırması sebebi ile "endüstri 4.0" ve "dijitalleşme" kavramları daha sık kullanılmaktadır. Fakat pazarlama amaçlı çok sık kullanılan başta endüstri 4.0 ve devamında nesnelerin interneti (IoT) ve büyük veri (big data) gibi terimlerin ne ifade ettiği gerçek anlamda bilinmemektedir (Rakyta, Fusko, Herčko, Závodská ve Zrnić, 2016: 439).

Endüstri 4.0 temelde sanayileşmenin dijitalleşmesi veya yeni teknolojiler vasıtasıyla fiziksel üretim ile siberin entegrasyonu olarak ifade edilmektedir (Vasin, Gamidullaeva, Shkarupeta, Palatkin, ve Vasina, 2018: 64). Bu entegrasyonun sağlanmasında bilgiyi üreten, bilgiyi tutan ve bilgiyi kullanan olmak üzere özellikle üç önemli teknoloji türü katkı sağlamaktadır (Winkelhaus ve Grosse, 2020: 33). Bu teknolojiler, Endüstri 4.0'ın tüm tedarik zinciri ve iş modellerini değiş̧irecek bir dönüşüm yaratmasını sağlamaktadır (Lee, Lv, Ng, Ho ve Choy, 2018: 2754). Özellikle ak1llı fabrikalarla birlikte bu teknolojilerin önemi daha da artmıştır.

Akıllı kavramının ilk kullanıldığı alanlardan biri akıllı fabrikalardır. Akıllı fabrikalar, üretim yapısında yaşanan hızlı değişimlere karşı esnek ve uyarlanabilir çözümler getiren fabrikalardır. Akıllı fabrikaların optimum üretim süreci gerçekleştirmek için uyguladıkları otomasyon teknolojilere donanım, yazılım ve mekaniğin bir araya getirilmesiyle gerçekleştirilir (Chong, Low, Mohammad, Rahman ve Shaari, 2018: 126). Dijital Dönüşüm sadece fabrikaların akıllı hale getirilmesini değil tüm tedarik zinciri yapısının akıllı hale getirilmesi gerektiğini öne sürmektedir. Tedarik zinciri süreçlerinin yapıtaşlarından biri olan lojistik süreçlerin de buna eşlik etmesi gerekmektedir. Dijital Dönüşüm temelli teknolojilerin lojistik alanında kullanılmasına "akıllı lojistik" veya "lojistik 4.0" denilmektedir (Müller ve Voigt, 2018: 122). Bu çalışmada "akıllı lojistik" teriminin kullanımı tercih edilmiştir. Akıllı lojistik alanında yapılan çalışmaları değerlendirdiğimizde öncelikle alanda akıllı lojistik "smart logistics" ve "logistics 4.0" kavramlarının birbiri yerine kullanılmasına rağmen birçok çalışmalarda bu kavramlardan sadece birinin seçilmesi ve bu iki kavram arasındaki eş anlamlılığın belirtilmemesi kavramsal karmaşa yaratmaktadır. Bu nedenle bu çalışmada "Akıllı Lojistik” kavramı kullanılmıştır.

$\mathrm{Bu}$ alanda yapılan literatür çalışmaları akıllı lojistik çerçevesinde ele alınmak yerine daha çok nesnelerin interneti, bulut bilişim, büyük veri vb. nitelikte bilgi iletişim teknolojileri odaklı bir çerçevede ilerlemiştir. Bu durum sağlanmak istenen lojistik süreçler arasındaki entegrasyon hedefinden dikkatlerin azalmasına ve bütünsel akıllı lojistik çerçevesinin oluşturulamamasına neden olmuştur. "Akıllı lojistik" özelinde yapılan çalışmaları değerlendirdiğimizde ise genel anlamda kısıtlı kaldığı gözlenmiştir. Akıllı lojistik çalışmalarının sayısı son yıllarda artmasına rağmen bu çalışmaların değerlendirilmesiyle ilgili sistematik literatür taraması sınırlıdır (Winkelhaus ve Grosse, 2020). Bu sınırlılıktan yola çıkarak, bu çalışma literatürdeki mevcut bilgiye sistematik bir yapı kazandırmayı ve hem akıllı lojistik hem de lojistikte 4.0 kavramlarını birlikte değerlendirerek daha bütüncül bir literatür taraması gerçekleştirmeyi hedeflemektedir. 
$\mathrm{Bu}$ çalışmanın ana amacı 2012-2020 yılları arasında akıllı lojistik alanında yapılan çalışmaların sistematik literatür taramasını gerçekleştirmek ve literatürdeki boşlukları ortaya koyarak bu alanda çalışacak araştırmacılara katkı sağlamaktır. Bu bağlamda ilk olarak çalışmanın tanımlayıcı unsurları ortaya konulmuş, daha sonrasında akıllı lojistiğin avantajları, uygulamada karşılaşılan zorluklar ve literatürdeki boşluklar değerlendirilmiştir.

\section{AKILLI LOJISTIK}

Lojistik; ürünün, sevkiyat noktasından teslimat noktasına ulaşıncaya kadar ki sürecini ifade etmektedir. Lojistik, ürünleri üretimden müşterilere ulaştıran ve tedarik zincirinin önemli bir aşamasını oluşturan modern toplumların dolaşım sistemidir (Wen, He, ve Zhu, 2018: 103). Lojistik faaliyetler; taşıma, depolama, sipariş ve stok yönetimi, gümrük, sigorta, muayene, paketleme ve katma değerli hizmetler gibi farklı süreçlerden oluşmaktadır. Bu süreçleri gerçekleştirirken firmaların birbirinden farklı hedefleri bulunmaktadır. Bazı firma için en uygun maliyetle iş yapmak önemliyken, bazıları içinse müşteriye en hızlı teslimatı gerçekleştirmek ya da en çevreye duyarlı lojistik ağı oluşturmak önemli olabilmektedir. $\mathrm{Bu}$ hedeflerin gerçekleştirilmesinde bilginin paylaşımı ve tedarik zinciri üyelerinin entegrasyonu kilit önem taşımaktadır. Endüstriyel süreçlerde olduğu gibi lojistikte geçmiş̧e üç büyük değiş̧im yaşamıştır. Gemi ve trenlerde buhar teknolojisinin kullanılmasıyla başlayan değişim, elektrik enerjisinin keşfiyle kargolama ve elleçleme süreçlerinin otomasyonuna ve devamında bilgi teknolojilerinin kullanılmasıyla lojistik bilginin sistemleştirilmesini sağlamıştır (Samir, Abdelsamad, Aziz ve Jamila, 2019: 534).

Son olarak ise dijital dönüşüm ile birlikte üretim ortamında otomasyon ve dijitalleşmenin artması ile ürünler çevre ve iş ortakları arasında dijital bir değer zinciri oluşturmaya başlanmıştır. Sürecin daha etkin ve verimli çalışabilmesi içinse tüm tedarik zincirinin ve lojistik süreçlerin benzer teknolojilerden faydalanarak entegrasyona sahip olmas1 gerekmektedir. Farklı aktörlerin uçtan uca entegrasyonu sağlamak, tedarik zinciri paydaşlarından biri olan müşteriye daha düşük bir maliyetle daha yüksek değer sunmayı mümkün kılmaktadır (Strandhagen, Vallandingham, Fragapane, Strandhagen, Stangeland ve Sharma, 2017: 361). Bu durum akıllı lojistik kavramının ortaya çıkmasını sağlamıştır. Akı1lı lojistik kavramını üçüncü lojistik devriminden ayıran en önemli nokta bilgiyi tek bir ortamda toplayarak teknolojiyle yakınlaştırmaktır (Levina ve Razumova, 2019: 272).

Ak1llı lojistik üç farklı boyutta değerlendirilebilir:

Yönetim; lojistik yönetim anlayışı dijitalleşme ile birlikte evrim geçirmektedir. Süreçlerin entegrasyonu daha uygun hale gelmekte, yönetim anlayışında yenilikler görülmekte ve bu çerçevede yatırımlar yapılmaktadır.

Malzeme akışı; malzeme akışında ise depoların otomasyonun ve robot kullanımının artması, nesnelerin interneti, 3 boyutlu yazıcılar ve arttırılmış gerçeklik teknolojilerinin kullanımı operasyon süreçlerini iyileştirmektedir.

Bilgi akışı; veri temelli hizmetler, büyük verinin kullanımı, RFID teknolojisi, gerçek zamanlı konum takibi, kurumsal kaynak planlaması ve depo yönetim sistemi gibi bilgi sistemleri kullanılmaya başlanmıştır (Facchini, Olésków-Szłapka, Ranieri ve Urbinati, 2020: 6).

Akıllı lojistik; esnekliği artmış, pazar ihtiyaçlarına göre kendini düzenleyebilen ve müşteriye daha yakın bir hale gelecek bir lojistik sistemdir (Barreto, Amaral ve Pereira, 2017: 1247). Gelecek on yıldaki en önemli gelişmelerden biri olarak kabul edilen akı1lı lojistik günlük hayatımızı önemli ölçüde değiştirebilir. Taşımacılık, stok yönetimi, malzeme elleçleme ve bilgi akış1 gibi ana lojistik süreçleri ak1llı lojistik dönüşümünden etkilenmiştir (Strandhagen vd., 2017: 363). Gerçekten de, depolama ve dağıtım şirketleri zaten yapay zeka (AI) kullanmış olup 
onlarca y1ldır robotikten, bilgi ve otomasyondan faydalanmaktadırlar (Wen, $\mathrm{He}$ ve $\mathrm{Zu}, 2018$ : 102). Akıllı lojistikte yaşanan bu gelişmenin ana nedenleri internet kullanımının hızlı bir şekilde artması ve gelişmiş dijital teknolojilerdir (Barreto vd., 2017: 1247). Akıllı lojistik, veriyi beklenen fayda doğrultusunda kullanabilme yeteneğine sahiptir (Yu, Jung ve Bae, 2015: 315).

"Covid 19" olarak da bilinen yeni tip korona virüsünün etkileriyle birlikte yaşanan süreçler de gösteriyor ki özellikle başta e-ticaret olmak üzere tüm firmalar için lojistik süreçler oldukça önemlidir. Bu bağlamda lojistiğin yedi doğrusu olarak bilenen doğru ürünü, doğru miktarda, doğru şartlarda, doğru yerde, doğru zamanda, doğru tüketiciye, doğru fiyatla ulaşmasını sağlama görevini yerine getirebilmesi için firmalar akıllı lojistik dönüşümüne ihtiyaç duyacaktır.

\section{YÖNTEM}

Literatür çalışmaları birincil çalışmaları değerlendirerek bulgular ortaya koyan çalışmalardır. Etkili bir literatür çalışması bilginin sağlam bir temele kavuşmasını sağlayarak ve çalışmaya geniş bir perspektiften bakarak araştırmanın gerekli olduğu alanları öne çıkarmaktadır (Webster ve Watson, 2002: 13). Bu çalışmada, sistematik haritalama yöntemi kullanılmıştır. Haritama derlemesi (Mapping review) olarak da ifade edilmektedir (Grant ve Booth, 2009: 97). Sistematik haritalama yöntemi, alanındaki çalışmaları haritalayarak literatürde yer alan eksikleri ortaya koymaya yardımcı olmaktadır (Petersen, Feldt, Mujitaba ve Mattsson, 2008). Literatür haritalama her adımın bir öncekine dayandığı, araştırma sorusuyla başlayan ve sistematik bir haritalama sona eren bir süreçtir (Wienhofen, Mathisen ve Roman, 2015: 3). Çalışmanın temel amacı ise "akıllı lojistik" ve "lojistik 4.0" olarak tanımlanan lojistik süreçlerin, bilgi iletişim teknolojilerinden yararlanılarak daha verimli ve daha sürdürülebilir hale getirilmesini içeren çalışmaları inceleyerek bir derleme ortaya çıkarmaktır. Akıllı lojistik çalışmalarının, literatürdeki lojistik çalışmaları içerisinde hangi alanlarda konumlandığını tespit etmek için sistematik yöntemi önerilmiştir. Sistematik haritalama yöntemi 5 aşamanın bir araya gelmesiyle oluşmaktadır. Bu aşamalar Şekil 1'de gösterilmiştir. 


\section{ÇALIŞMA ADIMLARI}

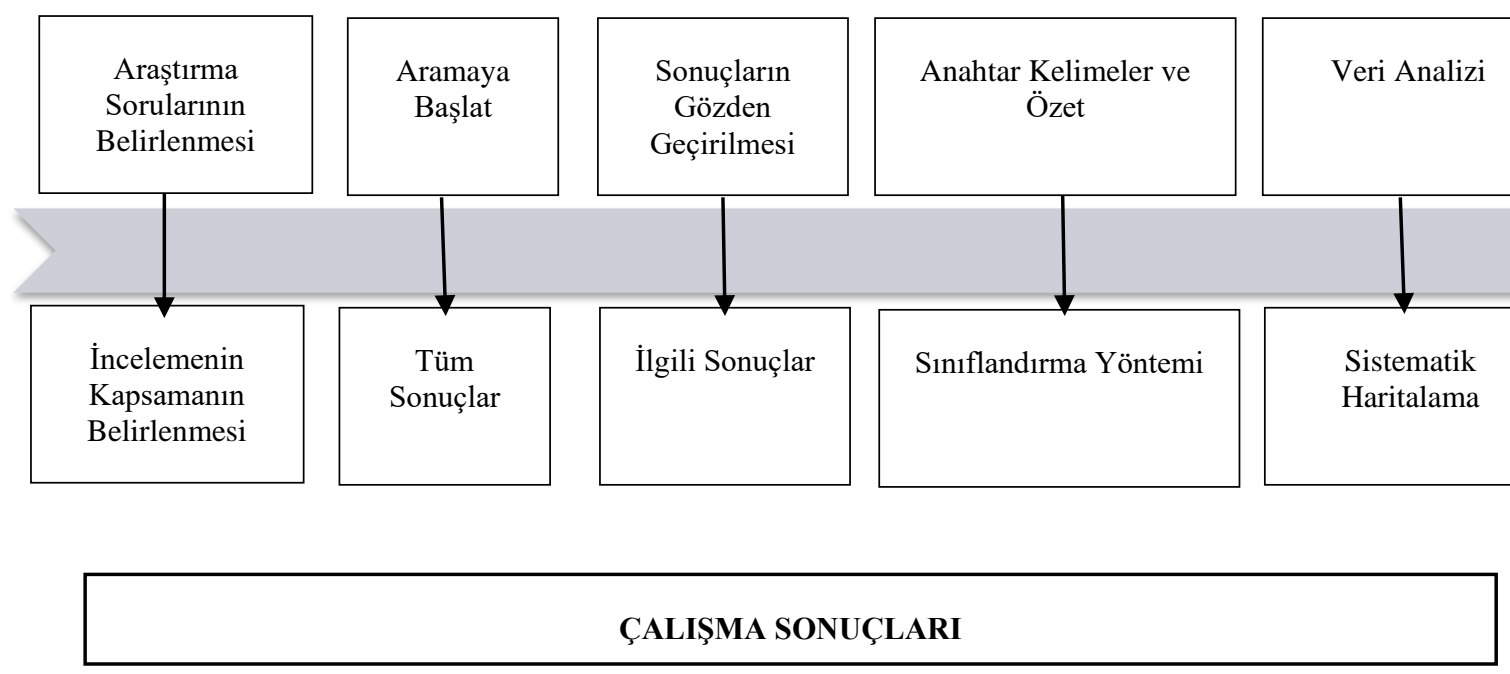

Şekil 1: Sistematik haritalama yöntemi aşamaları

Kaynak: (Petersen vd., 2008)

\section{1. Çalışma Sorularının Belirlenmesi}

Sistematik haritalama çalışmalarının ilk aşaması olan araştırma sorunlarının belirlenmesi çerçevesinde bu çalışmanın soruları ortaya konulmuştur. Çalışmada iki tür soru grubu oluşturulmuştur. İlk soru grubunda literatür hakkında genel bilgi oluşturmak amaçlanmaktadır. Birinci soru grubu;

1. 2012-2020 yılında yapılan çalışmaların yıllara göre yayın sayısı dağılımı nasıldır?

2. 2012-2020 yılında yapılan çalışmaların yıllara göre atıf sayısı dağılımı nasıldır?

3. 2012-2020 yılında yapılan çalışmaların yıllara göre dergilere dağılımı nasıldır?

4. 2012-2020 yılları arası akıllı lojistikle ilgili gerçekleştirilen çalışmaların konu başlıkları nelerdir?

İkinci tür sorularda ise literatürün daha ayrıntılı bir şekilde incelemeyi amaçlanmaktadır. İkinci soru grubu;

5. Akıllı lojistiğin sağladığı avantajlar nelerdir?

6. Akı1lı lojistik uygulamalarına geçişteki engeller nelerdir?

7. Akıllı lojistik alanına yönelik hangi alanlarda araştırma boşlukları mevcuttur?

\subsection{Veri Tabanı Taraması}

$\mathrm{Bu}$ çalışmada veri tabanı olarak en saygın bilimsel yayınların kabul edildiği "Web of Scince" ve "Scopus" seçilmiştir. Ayrıca Türkçe yayınları değerlendirmek amacıyla "Dergipark" veri tabanı dahil edilmiştir. Literatürde lojistik süreçlerin dijitalleşmesi veya bilgi teknolojilerinin lojistik alanında kullanılmasıyla ilgili çalışmalar mevcuttur. Ancak bu çalışmada akıllı lojistik kavramını içeren çalışmalar dikkate alındığı için anahtar kelime olarak; ingilizce "smart logistics", "smart logistic", "logistics 4.0" ve "logistic 4.0" kelimeleri taranmıştır. 
Dergipark'ta yapılan aramada ise bu kelimelerin Türkçe karşılığı olan "akı1lı lojistik" ve "lojistik 4.0" kelimeleri taranmıştır. Tarama Mart 2020 tarihinde gerçekleştirilmiştir.

\subsection{Veri Tabanı Sonuçlarının Değerlendirilmesi}

Tarama sonucunda ortaya çıkan bulgular belirli ön kriterler çerçevesinde değerlendirilmiştir. İlk olarak çalışmada bildiri, kitap, kitap bölümü, teknik rapor ve tez gibi kaynaklar elenerek sadece hakem sürecinden geçmiş makaleler dahil edilmiştir. Yayın dili olarak Web of Science ve Scopus için İngilizce ve Dergipark için Türkçe yazılmış çalışmalar dikkate alınmıştır. Son olarak belirlenen anahtar kelimelerin başlıkta, özette veya anahtar kelimenin birinde yer almasına dikkat edilmiştir.

Tarama sonucunda Web of Science veri tabanında 148 yayın tespit edilmiş ve bu yayınların 50 tanesini makaleler oluşturmaktadır. Scopus veri tabanında 245 yayın tespit edilmiş ve bu yayınların 81 tanesini makaleler oluşturmaktadır. Dergipark'ta ise 13 makale tespit edilmiştir. Toplamda 144 makale elde edilmiştir.

Sonuçlar amacına yönelik en ilgili makaleleri tespit etmek amacıyla veri tabanı bazında filtreleme yöntemi ile gözden geçirilmiştir. Filtreleme yönteminde tekrarlanan yayınların ve ilgisiz yayınların yer almamasına dikkat edilmiştir. İlk önce Web of Science veri tabanı değerlendirilmiş ve konuyla ilgisi olmayan çalışmalar çıkarılarak 41 makaleye düşürülmüştür. İkinci olarak Scopus veri tabanı değerlendirilmiş, Web of Science ile aynı olan yayınlar çıkarılmasıyla sayı 45'e düşürülmüş daha sonrasında ilgisiz yayınlar da çıkarılarak 19 makale olarak belirlenmiştir. Dergipark veri tabanında yapılan incelemede ise makale sayı 7'ye düşürülmüştür. Toplam 67 makale seçilmiştir.

\subsection{Anahtar Kelime ve Özet}

Çalışmanın dördüncü aşaması, anahtar kelime ve özet tarama sonucunda sınıflandırma oluşturulmasıdır. Dördüncü aşamada öncelikle özet ve anahtar kelimeler değerlendirilerek akıllı lojistik alanında yapılan çalışmaların yıllara göre dağılımı, atıfların yıllara göre dağılımı, bu alanda en çok yayın yapan dergiler ve hangi alanda çalışmaların yapıldığı gibi tanımlayıcı bulgular sınıflandırılmıştır. Daha sonra ise metinlerin tamamı değerlendirilerek hem ilk bulguların teyidi gerçekleştirilmiş hem de ikinci tür sorular için inceleme gerçekleştirilmiştir.

\section{BULGULAR}

Dijital dönüşüm ile lojistik alanında yükselişe geçen akıllı lojistik kavramı birçok sektör üyeleri ve lojistik firmaları tarafından farklı lojistik süreçlerin iyileştirilmesi için kullanılmaktadır. Yapılan literatür çalışması sonucunda elde edilen bulgular da bu iyileştirme çabalarını desteklemektedir.

\subsection{Yayınların yıllara göre dağılımı}

2012-2020 yılları arasında yapılan 67 çalışmanın yıllara göre dağılımı şekil 2'de gösterilmiştir. 


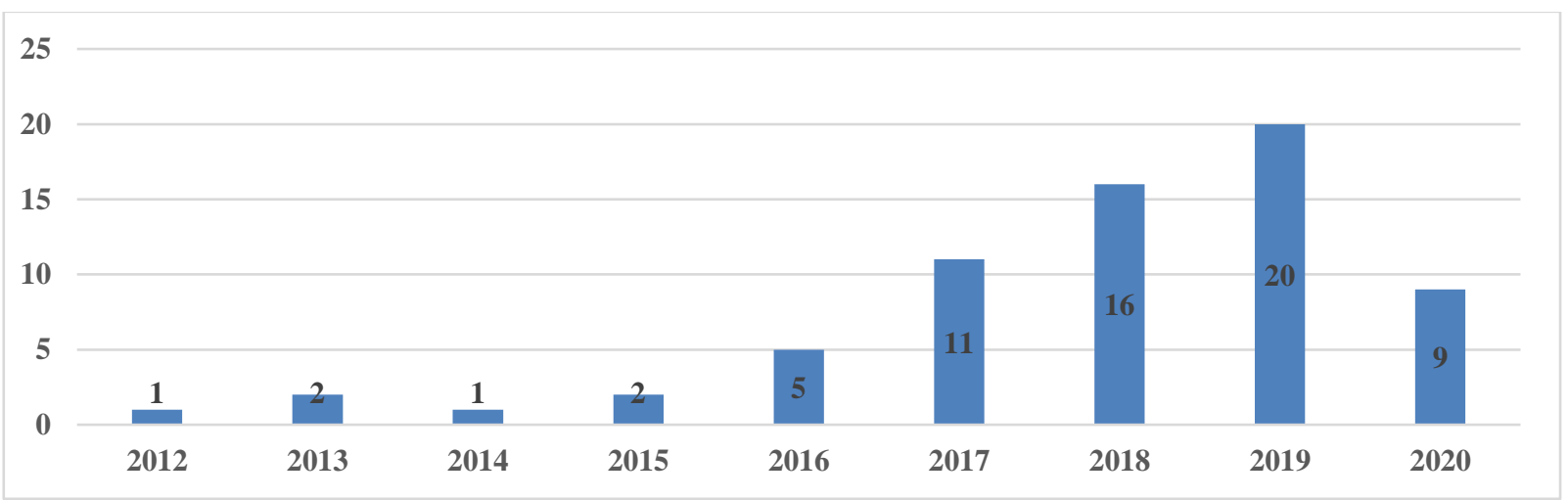

Şekil 2: Yayınların yıllara göre dağılımı

Akıllı lojistikle ilgili çalışmalar 2008 yılına dayansa da araştırmacıların bu alana yönelmesi özellikle 2015 y1lından sonra olduğu görülmektedir. 2015 yılından sonra yayın sayısında düzenli bir artış görülmekte ve 2019 yılında 20 yayınla zirve noktasına ulaşmıştır. 2020 yılının ilk üç ayında 9 çalışmaya ulaşmış ve bu alandaki ilginin devam ettiğini göstermiştir.

\subsection{Atıfların Yıllara Göre Dağılımı}

2012-2020 yılları arasında yapılan 67 çalışmanın atıf sayılarının yıllara göre dağılımı şekil 3'te gösterilmiştir.

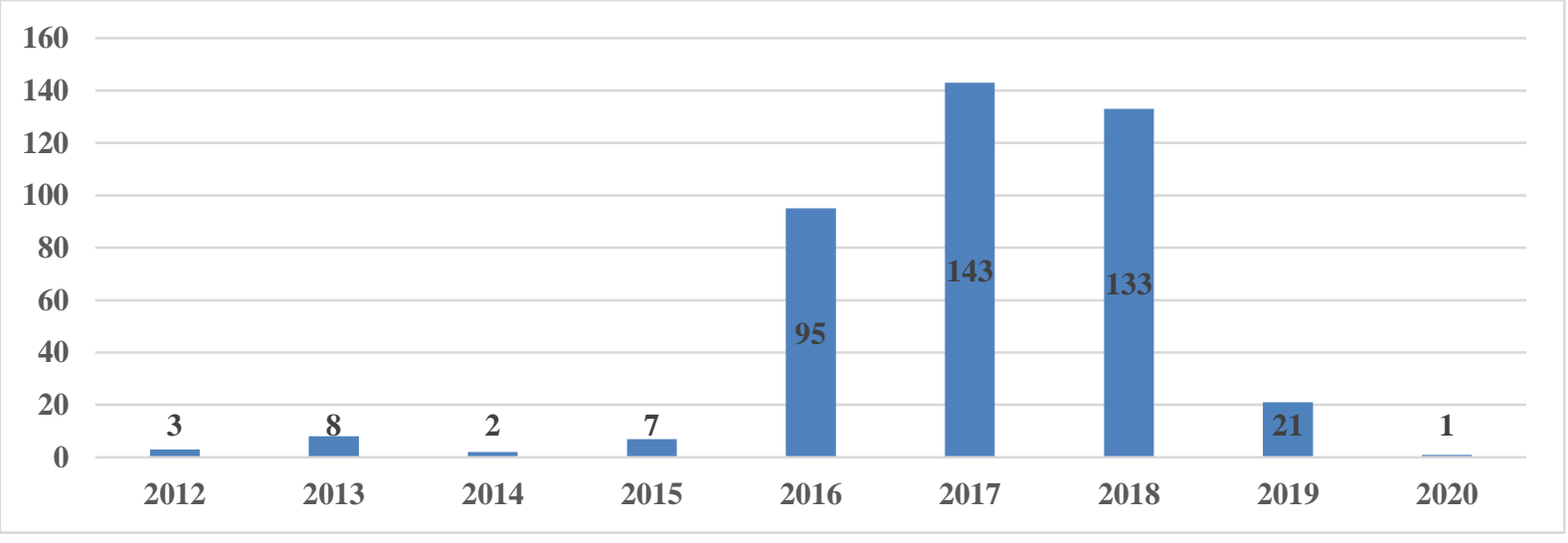

Şekil 3: Yayınların atıf sayılarının yıllara göre dağılımı

Akıllı lojistik alanında yapılan makalelerin atıf sayılarını değerlendirdiğimizde en çok atıf 2017 yılında yapılmıştır. Akıllı lojistik alanında çalışmaların son 5 yılda ortaya çıkması sebebiyle atıf sayıları da aynı yıllar içinde bir artış göstermektedir. En çok atıf alan makaleleri değerlendirdiğimizde ise Barreto vd. (2017); 73 atıf, S. Lee, Kang, ve Prabhu (2016); 43 atıf ve Ranieri, Digiesi, Silvestri, ve Roccotelli (2018); 32 atıf şeklinde olduğu görülmektedir.

\subsection{Yayınların Dergilere Göre Dağılımı}

2012-2020 yılları arasında yapılan 67 çalışmanın dergi bazında dağılımı şekil 4’te gösterilmiştir. 


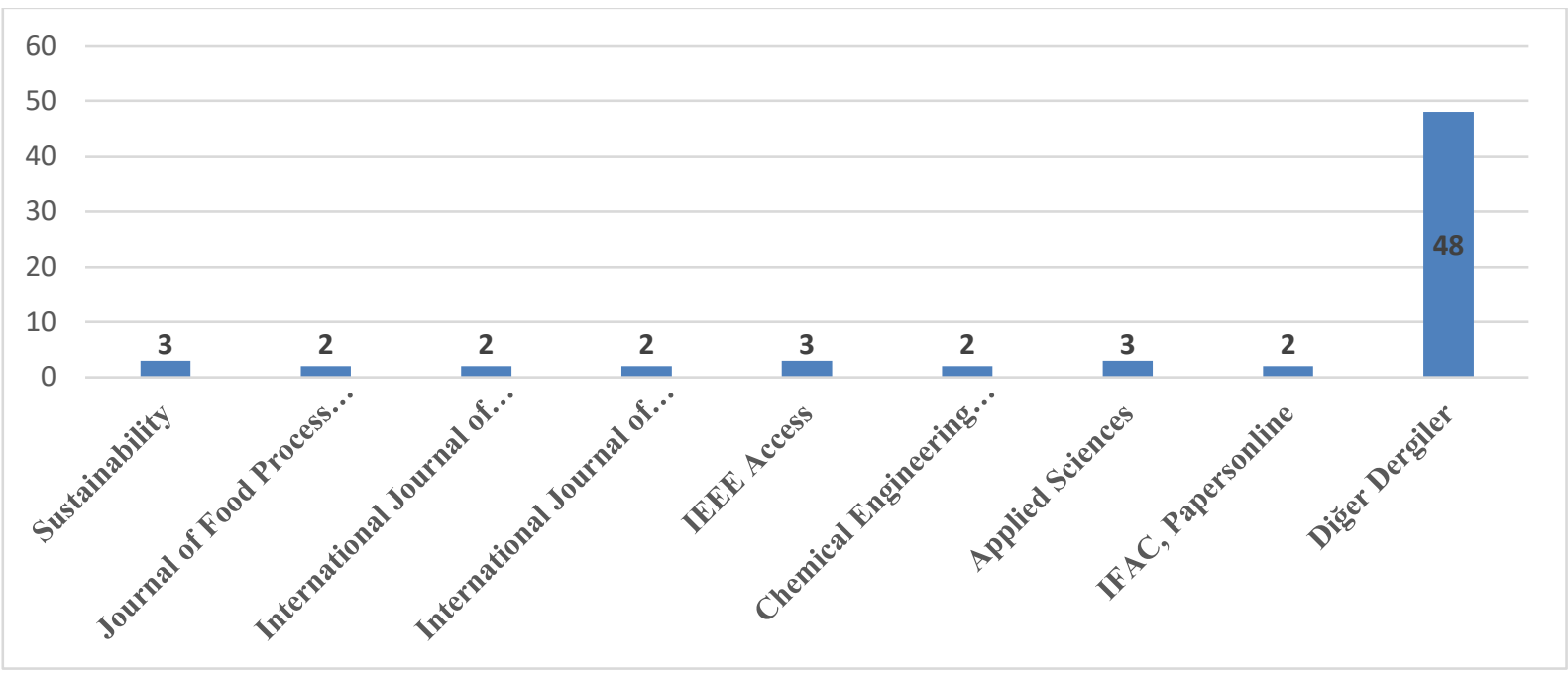

Şekil 4: Yayınların dergi bazında dağılımı

Makalelerin yayınlandığ 1 dergilerin geniş bir alana yayıldığı görülmektedir. 56 farklı dergide akıllı lojistikle ilgili çalışmalar bulunmaktadır. Dergileri sıraladığımızda "Sustainability" ve "Applied Science" bu alanda üçer adet yayınla en çok katkı sunan dergilerdir. Bu dergileri "International Production Research, International Production Economics, Journal of Food Process Engineering, IEEE Access, Chemical Engineering Transactions ve IFAC Papers online" ikişer yayınla takip etmektedir. Geri kalan 48 derginin ise birer yayını bulunmaktadır.

\subsection{Yayınların Konulara Göre Dağılımı}

Çalışmalar Liao vd., (2017;3613) dikkate alınarak dört grupta toplanmıştır; derleme ve anket çalışması, tartışma çalışmaları, teorik çözümler ve pratik çözümler.

Derleme ve anket çalışması: akıllı lojistik alanıyla ilgili yapılmış anketler ve derleme çalışmalarını kapsamaktadır.

Tartışma çalışmaları: akıllı lojistikle ilgili zorluklar, sorunlar, trendler üzerine yapılan çalışmaları dikkate almaktadır.

Teorik çözüm: lojistik sorunlarına akıllı lojistik teorik öneriler getiren çalışmaları dikkate almaktadır.

Pratik çözüm: lojistik sorunlara akıllı lojistik çözümler getiren ve bu çözümlerin pratik uygulamalarını değerlendiren çalışmaları kapsamaktadır. 
Tablo 1: 2012-2020 yılları arasındaki 67 çalışmanın konulara ve türlerine göre dağılımı

\begin{tabular}{|c|c|c|c|c|c|c|c|c|c|}
\hline & $\begin{array}{c}\text { Dijital } \\
\text { dönüşüm }\end{array}$ & Taşımacılık & $\begin{array}{c}\text { Depo } \\
\text { yönetimi }\end{array}$ & $\begin{array}{c}\text { Stok } \\
\text { yönetimi }\end{array}$ & $\begin{array}{c}\text { Risk } \\
\text { yönetimi }\end{array}$ & $\begin{array}{c}\text { BT } \\
\text { teknolojileri }\end{array}$ & $\begin{array}{c}\text { Yeşil } \\
\text { lojistik }\end{array}$ & $\begin{array}{c}\text { Lojistik } \\
\text { merkezler }\end{array}$ & Toplam \\
\hline $\begin{array}{l}\text { Derleme } \\
\text { ve anket }\end{array}$ & 10 & 1 & & & 1 & 1 & & & 14 \\
\hline $\begin{array}{l}\text { Pratik } \\
\text { çözüm }\end{array}$ & 7 & 1 & 2 & 3 & & & & & 13 \\
\hline Tartışma & 8 & 1 & 2 & 1 & 1 & 8 & 1 & & 20 \\
\hline $\begin{array}{l}\text { Teorik } \\
\text { çözüm }\end{array}$ & 4 & 4 & 3 & 3 & & & 4 & 1 & 20 \\
\hline
\end{tabular}

Akıllı lojistik çalışmalarını türlere göre sıraladığımızda 14 derleme ve anket çalışması, 13 pratik çözüm çalışması, 20 tartışma çalışması ve 20 teorik çözüm çalışması bulunmaktadır. Akıllı lojistik çalışmalarını değerlendirdiğimizde 29 dijital dönüşüm, 7 taşımacılık, 7 depo yönetimi, 7 stok yönetimi, 2 risk yönetimi, 9 bilgi iletişim teknolojileri, 5 yeşil lojistik ve 1 lojistik merkez çalışması bulunmaktadır.

Dijital dönüşüm başlığı akıllı lojistikle ilgili genel kapsam çalışmalarını içermektedir. Dijital dönüşüm alanında 10 derleme ve anket çalışması bulunmaktadır. Sivamani, Kwak ve Cho (2014) müşteri merkezli akıllı lojistik hizmet modeli önermiștir. Özdemir ve Özgüner (2018) kavramsal bir değerlendirme gerçekleştirerek dijital dönüşümün lojistik üzerindeki etkilerini değerlendirmiştir. Bakan ve Şekkeli (2018) endüstri 4.0'ın lojistik sektörüne etkilerini değerlendirmiştir. Öztemel ve Gürsev (2018) çalışmalarında, Türkiye'de lojistik sektörünün endüstri 4.0'a etkileri ve yatırım imkânlarına bakışı üzerine anket uygulaması gerçekleştirmiştir. Ranieri vd. (2018) yenilikçi stratejilerin son kilometre lojistiğine etkisiyle ilgili literatür taraması gerçekleștirilmiştir. Frazzon, Rodriguez, Pereira, Pires ve Uhlmann (2019) tedarik zinciri 4.0 ve lojistik 4.0 üzerine bibliyometrik bir analiz gerçekleştirmiştir. Levina ve Razumova (2019) Rusya lojistik sürecinin dijitalleşmesi ve bilgi sistemleri entegrasyonunu vaka analiziyle değerlendirmiştir. Yılmaz ve Duman (2019) lojistik 4.0 kavramını tarihsel perspektiften değerlendirmiştir. Karagöz ve Bumin Doyduk (2020) derinlemesine mülakat yöntemiyle Türk lojistik sektörünün lojistik 4.0 kavramına bakış açısını ortaya koymuştur. Türkmenoğlu (2020) dijitalleşmenin lojistik yönetimine etkileri bağlamında kavramsal değerlendirilmesini gerçekleştirmiştir.

Pratik çözüm çalışmalarında; Tatham, Stadler, Murray ve Shaban (2017) tıbbi ürünleri taşımak için uzaktan kumandalı uçak kargo modeli önermiş ve test etmiştir. Luo ve Fu (2017) tehlikeli kimyasal madde lojistiğinin akıllı izleme sistemini önermiştir. Chong vd. (2018) veri temelli lojistik yönetim sistemi önermiştir. Bosona, Gebresenbet, Olsson, Garcia ve Germer (2018) biokütle üzerine bir akıllı lojistik sistem önermiş ve bir vaka üzerinde test etmiştir. Facchini vd. (2020) lojistik 4.0 temelli olgunluk modeli önerisi getirmiştir. Frontoni, Rosetti, Paolanti ve Alves, (2020) taşıma firması için akıllı lojistik temelli model önerisi getirip vaka analiziyle test etmiştir. Gebresenbet, Bosona, Olsson ve Garcia (2018) akıllı lojistik sistem uygulamasının gerçek vaka üzerinde etkilerini ortaya koymuştur.

Tartışma çalışmalarında; Pan (2012) akıllı lojistik üzerinde bulanık AHS yöntemiyle bir değer zincir analizi gerçekleştirmiştir. Xu vd. (2013) vaka analiziyle akıllı lojistik platformu analiz etmiştir. Rakyta vd. (2016) akıllı lojistik yönetiminde proaktif yaklaşımının önemini analiz etmiştir. Strandhagen vd. (2017) lojistik 4.0 ile oluşan yeni iş modellerini 
değerlendirmiştir. Delfmann, Ten Hompel, Kersten, Schmidt ve Stölzle (2018) endüstri 4.0 uygulamalarının lojistik 4.0 üzerindeki rolünü değerlendirmiştir. Cimini, Lagorio, Pirola, ve Pinto (2019) akıllı lojistiğin işgücüne etkisini bir vaka analizi üzerinde değerlendirmiştir. Krykavskyy vd. (2019) Ukrayna'nın akıllı lojistiğe dönüşüm nedenleri ve karşılaştıkları sorunlar ikincil veri ve anketlerle analiz etmiştir. Stachowiak, Adamczak, Hadas, Domanski ve Cyplik, (2019) derinlemesine mülakat yöntemiyle firmaların olgunluk düzeyinin bilgi edinme kapasitesine etkisini araştırmıştır.

Teorik çözüm çalışmaları; . Yu vd. (2015) CBS temelli lojistik süreç izleme modeli önermiştir. Xie (2018) Çin tehlikeli kimyasal madde lojistiğinde akıllı lojistik uygulamalarının durumunu değerlendirmiştir. Bukowski (2019) eksik bilgi durumunda büyük veri kullanarak karar destek modeli önerisi getirmiştir. Hasan, Jiang, Ullah ve Noor-E-Alam (2020) Bulanık TOPSIS ve çok seçenekli hedef programlama yöntemiyle lojistik 4.0 etkisiyle tedarikçi seçimi gerçekleştirmiştir.

Taşımacılık alanında derleme ve anket çalışması; Baykasoğlu, Subulan, Taşan ve Dudaklı, (2019)Rusya taşımacılık sektörü açısından dijitalleşmenin durumu ortaya konulmuştur. pratik çözüm çalışması; La Scalia vd. (2016) taşımacılık sırasında vibrasyonun kolay bozulan ürünlerin raf ömrüne etkisini incelemiştir. Tartışma çalışması; Hsiao ve Chang (2019) dijital ses asistanının lojistik hizmetlerdeki önemini AHS yöntemiyle araştırmıştır. Teorik çözüm çalışmaları; Lin, Shi, Zhang ve Wang (2019) nesnelerin interneti entegreli kapasiteli optimum araç rotalama problemi çözümü gerçekleştirmiştir. Sicari, Rizzardi ve Coen-Porisini (2019) akıllı lojistik uygulaması önermiştir. Su ve Fan (2020) akıllı lojistik çerçevesinde optimum yeşil araç rotalama gerçekleştirmiş̧tir. Zhang (2018) akıllı lojistik karar modeli önermiştir.

Depo yönetimi ile ilgili çalışmalar; tartışma, teorik ve pratik çözüm önerilerinden oluşmaktadır. Tartışma çalışması Trab vd., (2017) konuşan nesnelerin akıllı lojistik sistemlerin performansına etkisini değerlendirmiştir. Wen vd. (2018)'in robot sürülerinin akıllı lojistik alanında kullanılması üzerine karşılaşılan sorunların değerlendirildiği çalışmadır. Pratik çözüm çalışmaları incelediğimizde Zhou, Piramuthu, Chu, ve Chu (2017) Akıllı depo yönetimi üzerine bir model sunmuştur. Lee vd. (2018) akıllı depo yönetimi üzerine bir model sunmuştur. Teorik çözüm çalışmaları; Cui (2017), Jabbar, Khan, Silva ve Han (2018) ve Lee vd. (2019) çalışmalarında akıllı depo yönetimi ile ilgili model önerileri getirmiştir.

Stok yönetimi alanında pratik çözüm çalışmaları; La Scalia, Nasca, Corona, Settanni ve Micale (2017) kolay bozulan ürünler için bir akıllı lojistik modeli önermiş ve vaka üzerinde test etmiştir. La Scalia vd. (2016) Raf ömrü üzerine bir model önerisi geliştirmiş ve test etmiştir. Micale, Enea ve La Scalia (2016) raf ömrü tahmini için model önerisi getirmiş ve bir vaka üzerinde test etmiştir. La Scalia, Micale, Certa, ve Enea (2015) akıllı lojistik temelli farklı raf ömrü modellerini karşılaştırmıştır. Teorik çözüm çalışmaları; Anandhi, Anitha ve Sureshkumar (2019) ve Bosona, Gebresenbet, ve Olsson (2018) ürün takibi için yeni model önerileri getirmişlerdir. Chen, Ma, Wang, Wang ve Yu (2018) RFID tabanlı çok kategorili stok sistemi önermiştir.

Risk yönetimi alanında tek derleme ve anket; Barczak, Dembińska ve Marzantowicz (2019) tarafindan dijitalleşmenin lojistik yönetimine getirdiği değişikler ve oluşan risklerin anket yöntemiyle araştırılmasıdır. Tek tartışma çalışmasında ise; Kodym, Kubáč ve Kavka (2020) Lojistik 4.0 uygulamasının risklerini değerlendirmişlerdir.

Bilgi iletişim alanındaki çalışmaları incelediğimizde 1 adet derleme ve anket çalışması bulunmaktadır. Erkollar ve Oberer (2017) lojistik süreçler için kullanılan FLEXTRANS 4.0 uygulamasını değerlendirmiştir. Tartışma çalışmaları; Barreto vd. (2017) endüstri 4.0 uygulamalarının lojistik süreçlere etkisini değerlendirmiştir. Cho ve Kim (2017) nesnelerin interneti tabanlı güvenli taşıma modeli önermiştir. Büyüközkan (2012) lojistik 4.0 
kapsamında mevcut teknolojilerin bulanık AHS ile analizini sağlayan bir model önermiştir. Poenicke, Groneberg ve Richter (2019) nesnelerin internetinin ak1ll lojistik üzerindeki etkilerine kavramsal bir değerlendirme getirmiştir. Samir vd. (2019) yeşil nesnelerin interneti ve büyük verinin lojistik analizlerde kullanımını değerlendirmiştir. Teucke, Broda, Börold ve Freitag (2018) sensör verilerin otomobil tedarik zinciri üzerindeki etkilerini simülasyonla analiz etmiştir. Trappey vd. (2017) nesnelerin interneti tabanlı teknolojilerin akıllı lojistik üzerinde kullanımını incelemiştir. Ellefsen, Oleśków-Szłapka, Pawłowski ve Toboła (2019) Yapay zeka uygulamalarının olgunluk modeli süreçlerinde kullanımını incelemiştir.

Yeşil lojistik alanındaki çalışmaları incelediğimizde tartışma çalışması; Sutawijaya ve Nawangsari (2020) endüstri 4.0'ın yeşil tedarik zincirine etkilerini araştırmış̧ır. Teorik çözüm çalışmaları; Hilpert, Kranz ve Schumann (2013) sera gazı salınımı takip sistemini önermiştir. S. Lee, Kang, ve Prabhu (2016) isteğe bağlı parsel teslimat hizmetleri için entegre bir karar verme çerçevesi geliştirmiştir. Ma, Wang, Bai ve Wang (2020) soğuk zincir lojistiği için koordinasyon modeli önermiştir. Sarkar, Guchhait, Sarkar ve Cárdenas-Barrón (2019) akıllı lojistik sistemlerinin karbon salınımını dikkate alarak optimum nakit akışı nasıl oluşturduğunu incelemiştir. Lojistik merkez alanında tek bir makale olup Yavas ve Ozkan-Ozen (2020) lojistik merkezler üzerine bir model önerisi getirerek teorik çözüm çalışmasını içermektedir.

\subsection{Akıllı Lojistiğin Getirdiği Avantajlar}

Endüstri 4.0'daki gelişmeler lojistik süreçlerini de büyük ölçüde etkileyerek akıllı lojistiğin ortaya çıkmasını sağlamıştır. Akıllı lojistik; şirketlere iş modelleri, operasyon modelleri, iletişim modelleri gibi birçok konuda önemli katkılar sunmaktadır. Bu katkıların bir kısmı aşağıda sıralanmıştır.

Entegrasyon: Tedarik zincirinin en önemli amaçlarından biri olan tam entegrasyonu sağlayarak bütüncül bir sistem gibi çalışabilmektedir. Akıllı lojistik bilgi iletişim teknolojilerinden faydalandığı için bilginin ve malzemenin akışı daha hızlı ve güvenli bir şekilde gerçekleştirilebilmektedir ( Lee vd., 2019; Levina ve Razumova, 2019; Winkelhaus ve Grosse, 2020)

İzlenebilirlik: Akıllı lojistik, tüm süreçlerin izlenebilmesi ve takip edilebilmesi için barkod, RFID, GPS vb. elektronik tanımlama ve takip sistemleri kullanılmaktadır. Bu sayede süreçlerle ilgili verilere ulaşılabilmekte ve uygun çözümler getirilebilmektedir (Sutawijaya ve Nawangsari, 2020; Barreto vd., 2017).

Maliyetlerin azalması: akıllı lojistiğin uygulamalar gerçekleştirdiği alanda önemli maliyet avantajları elde ettiği görülmektedir (Frontoni, Rosetti, Paolanti, ve Alves; Gebresenbet, Bosona, Olsson, ve Garcia, 2018; Lee, Kang, ve Prabhu, 2016).

Verimlilik: akıllı lojistik süreçlerinin entegrasyonu ve otomasyonunda, robotik teknolojilerden faydalanılması, ölçek ekonomisinin sağlanması ve insana dayalı hataların azaltılması önemli bir verimlilik avantajı getirmiştir (Lee vd., 2018; Winkelhaus ve Grosse, 2020).

Müşteri taleplerini daha doğru anlama: bilgi iletişim teknolojileri farklı verileri bir araya getirerek büyük veri analiz yöntemleri sayesinde müşterilerin talep ve tercihlerini anlamakta ve uygun çözümler getirebilmektedir (Lee vd., 2018; Schumann, Leye ve Popov, 2015; Winkelhaus ve Grosse, 2020).

Tam zamanında teslimat: Şirketlerin maliyetlerini düşürmeleri kadar tüketiciye tam zamanında teslimat yapmaları da oldukça önemlidir. bilgi iletişim teknolojileri sayesinde elde edilen verilerin analizi sonucunda hem verimsiz noktaların tespit edilmesi hem de teslimat 
zamanlaması konusunda doğru bilginin müşterilere ulaştırılmasına katkı sunmaktadır (Sicari, Rizzardi ve Coen-Porisini, 2019; Sutawijaya ve Nawangsari, 2020).

Fazla üretimin engellenmesi: Entegrasyon ve bilginin hızlı akışı sayesinde daha doğru talep tahmini oluşturularak fazla üretim engellenmektedir (Frontoni vd., 2020).

Aşırı stok tutulmasının engellenmesi: Talep doğru tahmin edildiğinde ve süreç içerisinde bilgiye daha hızlı ulaşıldığında üretim daha hızlı gerçekleştirilmekte ve gereksiz stok tutulmak zorunda kalmamaktadır (Chen vd., 2018; Teucke vd., 2018; Zhou vd., 2017).

Yeşil lojistik: Akıllı lojistik yönetimi tüm süreçlerde maksimum verimlilikle çalıştı̆̆ 1 için başta emisyonun azaltılması, enerji tüketiminin azaltılması, kaynak kullanımının azaltılması gibi konularda çevreye önemli katkılar sunmaktadır (J. Chen, Huang, Xie, Lee, ve Hua, 2019; Lee vd., 2016).

\subsection{Akıllı Lojistik Uygulamalarının Engelleri}

Akıllı lojistik uygulamalarının önünde birçok engel bulunmaktadır. Bu alandaki engellerin birçoğu dijital dönüşümde yaşanan engellerle benzerlik göstermektedir. Akı1lı lojistikle ilgili engeller aşağıda verilmiştir (Barreto vd., 2017; Kodym vd., 2020; Winkelhaus ve Grosse, 2020; A. Zhang vd., 2019).

\section{Teknolojik engeller;}

- Tüm süreçlerin siber ortamda yürümesi bu alanda firmaya yapılacak saldırıların üretimi/hizmeti engellemesi ve verilerin çalınma ihtimali

- Akıllı lojistik teknolojilerini kullanacak nitelikli yeterli personel bulunmaması ve var olan personeli sürekli eğitme zorunluluğu

- Kullanılan teknolojilerin birbiriyle entegrasyon gerektirmesi

\section{Ekonomik engeller;}

- Bilgi teknoloji yatırımlarının yüksek maliyetli olması

- Akıllı lojistik yatırımında özellikle kullanılan birçok teknolojinin yeni gelişmesi ve hangi teknolojinin daha verimli olacağını veya tüketici veya diğer şirketler tarafindan tercih edileceği

\section{Sosyal engeller;}

- Daha az insana ihtiyaç duyulmas1

- Yaşlı çalışanların teknoloji kullanım kabiliyetinin düşük olması ve bu teknolojileri desteklememesi

- Kurum kültürünün akıllı lojistik uygulamalarına geçişe izin vermemesi

\section{Ekolojik riskler;}

- Akıllı lojistik yatırımları enerji tüketimi ve emisyonu işlem bazında düşürse bile burada kullanılacak teknolojilerin getirdiği enerji tüketimi artış1

- Makro ölçekte ekonomik büyümenin getirmiş olacağı harcamalar

\section{Hukuki ve politik riskler}

- Regülasyonların eksik olması

- Teşviklerin olmaması 


\subsection{Literatürdeki Boşluklar}

Akıllı lojistik kavramının yeni olması ve son yıllarda önem kazanması sebebiyle kaynakların birçoğu teknoloji temelli modeller önermekte ve kavramsal değerlendirmelere yönelmektedir.

- Özellikle önerilerin model uygulamalarının sonuçları değerlendirilebilir veya kavramsal değerlendirilmelerin ampirik analizleri gerçekleştirilebilir.

- İnsan faktörünün akıllı lojistikle birlikte ne yöne evirileceği incelenebilir.

- Organizasyon içinde ve organizasyonlar arasında değişen yönetim yapıları özellikle ülke kültürü ve organizasyon kültürü özelinde değerlendirilebilir.

- Teknoloji kabul modelleriyle kullanıcıların bu teknolojileri kabulü araştırılabilir.

- Akıllı lojistik çalışmalarının önemli bölümünün depo yönetimiyle ilgili süreçlere yöneldiği, özellikle taşımacılık süreçleri başta olmak üzere elleçleme, paketleme, gümrükleme gibi süreçler de dikkate alınabilir.

- Dijital dönüşüm kavramıyla birlikte siber fiziksel iletişim ve bu iletişimi gerçekleştiren nesnelerin internetinin çalışmaların ana teknoloji konusu olduğu gözlenmiştir. Diğer bilgi teknolojileriyle; büyük veri, üç boyutlu yazıcılar, sanal gerçeklik, arttırılmış gerçeklik, robotik teknolojilerin kullanımı ilgili çalışmalar gerçekleştirilebilir.

- Dijital dönüşüm kavramını otonom, akıllılık, makineler arası iletişim gibi teknolojilerin tedarik zincirinin entegrasyonuna etkileri deneysel çalışmalarda analiz edilebilir.

- Sürdürülebilir lojistik konusunda akıllı lojistik uygulamaların geliştirilmesi, özellikle ak1llı lojistiğin Avrupa Birliği'nin 2020 vizyonu çerçevesinde yöneldiği döngüsel ekonomiye katkıları değerlendirilebilir.

- Türkiye'de yapılan çalışmaların konusu kavramsal değerlendirmeler ve anket temelli sektörün bakış açısını değerlendiren çalışmalardan oluşmaktadır. Akıllı lojistik uygulamalarının Türkiye'de uygulamasına yönelik engeller ve uygulanabilecek akıllı lojistik önerileri gibi çalışmalar gerçekleştirilebilir.

\section{SONUÇ}

Bu çalışmanın hedefi akıllı lojistik alanında sistematik literatür taraması gerçekleştirerek $\mathrm{bu}$ alandaki çalışmaların durumunu ortaya koymaktır. Akıllı lojistikle ilgili çalışmaları incelediğimizde bu çalışmaların endüstri 4.0 girişiminin ortaya çıkmasıyla birlikte yoğunlaştığı gözlenmektedir. Tedarik zinciri süreçlerinden biri olan lojistik faaliyetler, dijital dönüşümünden payını almıştır. Akıllı lojistik ile ilgili çalışmaları incelediğimizde kavramsal açıdan "akıllı lojistik" (smart logistics) ve "lojistik 4.0" (logistics 4.0) olmak üzere iki terimin yoğun olarak kullanıldığg belirlenmiş̧ir.

Dijital dönüşüm teknolojilerinin uygulanması şirketlerde süreçler, insan kaynakları, organizasyon ve kültür gibi birçok konuda değişime neden olacaktır. İşin temelinde uçtan uca entegre altyapı, uzmanlık, veri ve veri analitiği konuları yatmaktadır. Şirketlerde dijital kültür oluşturmak uzun vadeli bir iştir. Bu teknolojiler ile şirket yalınlı̆̆ 1 ve çevikliği artacaktır. Bu sürece stratejik açıdan yaklaşıldığında 4-5 yıl gibi bir süre alacağı ve önemli ölçüde yatırım finansmanı gerektireceği gözden uzak tutulmamalıdır. Dolayısıyla önce dijital olgunluk düzeyinin tespiti yapılarak dijital dönüşüm stratejisinin ve yol haritasının belirlenmesi gerekmektedir. Bu projenin sponsoru da şirketin en düzey yöneticilerinden biri olmalıdır.

$\mathrm{Bu}$ çalışmanın tanımlayıcı ve tematik bulguları değerlendirdiğimizde üç ana unsur öne çıkmaktadır. İlk olarak, akıllı lojistik ile ilgili yapılan çalışmalar 2015 yılı itibariyle çalışmaların sayısının arttığı, atıf sayısı açısından ise 2016, 2017 ve 2018 yıllarındaki çalışmaların atıf 
sayılarında belirgin bir artış olduğu görünmektedir. Ayrıca akıllı lojistik alanındaki çalışmalar farklı alanlardaki dergilerde kendilerine yer bulduğu tespit edilmiştir.

İkinci olarak, çalışmaların türlerine göre değerlendirdiğimizde en çok derleme-anket ve tartışma makalelerin yoğun olduğu gözlenmiştir. Bu durumun temel sebebi olarak akıllı lojistik kavramının yeni başlamış olması ve bu alanda pratik çözümler sunacak kadar yoğun uygulamaların olmadığı düşünülmektedir. Çalışmaların konularını değerlendirdiğimizde ise en çok dijital dönüşüm olarak isimlendirdiğimiz genel kapsayıcı makalelerin olduğu gözlenmiştir. Bu makaleler genel olarak geleneksel lojistiğin dijital dönüşümünü kavramsal, anket, nitel vb. yöntemlerle değerlendiren çalışmalardan oluşmaktadır.

Son olarak, akıllı lojistiğin faydalarını değerlendirdiğimizde ise var olan çalışmalar dijital dönüşümün lojistik süreçlere temel anlamda önemli katkılar sunduğunu göstermektedir. Başta maliyet verimlilik, izlenebilirlik gibi unsurlar olmak üzere önemli avantajlar sunduğu tespit edilmiştir. Bununla birlikte dijital dönüşüm siber ve fiziksel riskler, insan gücünün ne olacağ barındırmaktadır. $\mathrm{Bu}$ durum şirketler arası tedarik zinciri bazında düşünüldüğünde hukuki konular ortaya çıkacaktır.

Bu çalışma yazına iki önemli katkı sunmaktadır. İlk olarak gelişmekte olan akıllı lojistik literatürünün mevcut durumuna yönelik tanımlayıcı istatistiklerin ortaya konulmasını sağlamaktadır. İkinci olarak da literatürdeki çalışma alanlarını haritalayarak boşlukların belirlenmesi ve gelecek çalışmalara yol gösterici öneriler sunmaktadır.

Çalışmanın sınırlılıkları; anahtar kelime olarak sadece akıllı lojistik alanına odaklanılması dijital dönüşümü içeren diğer çalışmaların incelenmemesine neden olmuştur. Ayrıca çalışmalarda yapılan konu gruplandırması bazı noktalarda öznellik taşımaktadır.

\section{KAYNAKÇA}

Anandhi, S., Anitha, R. ve Sureshkumar, V. (2019). IoT enabled RFID authentication and secure object tracking system for smart logistics. Wireless Personal Communications, 104(2), 543-560.

Bakan, İ. ve Şekkeli, Z. H. (2018). Endüstri 4.0 etkisiyle lojistik 4.0 Journal of Life Economics, 5(2), 17-36.

Barczak, A., Dembińska, I. ve Marzantowicz, Ł. (2019). Analysis of the risk impact of implementing digital innovations for logistics management. Processes, 7(11), 1-16.

Barreto, L., Amaral, A. ve Pereira, T. (2017). Industry 4.0 implications in logistics: an overview. Procedia Manufacturing, 13, 1245-1252.

Baykasoğlu, A., Subulan, K., Taşan, A. S. ve Dudaklı, N. (2019). A review of fleet planning problems in single and multimodal transportation systems. Transportmetrica A: Transport Science, 15(2), 631-697.

Bilgiç, E., Türkmenoğlu, M. A. ve Koçak, A. (2020). Derleme Makale / Review Article Dijitalleşmenin Lojistik Yönetimi Bă̆lamında İncelenmesi *. 5(1), 56-69.

Bosona, T., Gebresenbet, G. ve Olsson, S. O. (2018). Traceability system for improved utilization of solid biofuel from agricultural prunings. Sustainability (Switzerland), 10(2), 1-12.

Bosona, T., Gebresenbet, G., Olsson, S. O., Garcia, D. ve Germer, S. (2018). Evaluation of a smart system for the optimization of logistics performance of a pruning biomass value chain. Applied Sciences (Switzerland), 8(10), $1-18$.

Bukowski, L. (2019). Logistics decision-making based on the maturity assessment of imperfect knowledge. Engineering Management in Production and Services, 11(4), 65-79.

Büyüközkan, G. (2012). An integrated fuzzy multi-criteria group decision-making approach for green supplier evaluation. International Journal of Production Research, 50(11), 2892-2909.

Chen, H., Ma, G., Wang, Z., Wang, Q. ve Yu, J. (2018). MAC: Missing tag iceberg queries for multi-category RFID systems. IEEE Transactions on Vehicular Technology, 67(10), 9947-9958. 
Chen, J., Huang, T., Xie, X., Lee, P. T. W. ve Hua, C. (2019). Constructing governance framework of a green and smart port. Journal of Marine Science and Engineering, 7(4), 1-17.

Cho, S. ve Kim, J. (2017). Smart logistics model on internet of things environment. Advanced Science Letters, 23(3), $1599-1602$.

Chong, Z. Q., Low, C. Y., Mohammad, U., Rahman, R. A. ve Shaari, M. S. B. (2018). Conception of logistics management system for smart factory. International Journal of Engineering and Technology(UAE), 7(4), 126131.

Cimini, C., Lagorio, A., Pirola, F. ve Pinto, R. (2019). Exploring human factors in Logistics 4.0: Empirical evidence from a case study. IFAC-PapersOnLine, 52(13), 2183-2188.

Cui, W. (2017). An optimization model for storage robot adaptive positioning system (SR-APS) and simulation analysis. Boletin Tecnico/Technical Bulletin, 55(16), 484-491.

Delfmann, W., Ten Hompel, M., Kersten, W., Schmidt, T. ve Stölzle, W. (2018). Logistics as a science: Central research questions in the era of the fourth industrial revolution. Logistics Research, 11(9), 1-13.

Ellefsen, A. P. T., Oleśków-Szłapka, J., Pawłowski, G. ve Toboła, A. (2019). Striving for excellence in ai implementation: Ai maturity model framework and preliminary research results. Logforum, 15(3), 363-376.

Erkollar, A. ve Oberer, B. (2017). Flextrans 4.0-Smart Logistics for Smart Cities. SIGMA Journal of Engineering and Natural Sciences, 8(4), 269-277.

Facchini, F., Olésków-Szłapka, J., Ranieri, L. ve Urbinati, A. (2020). A maturity model for logistics 4.0: An empirical analysis and a roadmap for future research. Sustainability (Switzerland), 12(1), 1-18.

Frazzon, E. M., Rodriguez, C. M. T., Pereira, M. M., Pires, M. C. ve Uhlmann, I. (2019). Towards Supply Chain Management 4.0. Brazilian Journal of Operations ve Production Management, 16(2), 180-191.

Frontoni, E., Rosetti, R., Paolanti, M. ve Alves, A. C. (2020). HATS project for lean and smart global logistic: A shipping company case study. Manufacturing Letters, 23, 71-74.

Gebresenbet, G., Bosona, T., Olsson, S. O. ve Garcia, D. (2018). Smart system for the optimization of logistics performance of the pruning biomass value chain. Applied Sciences (Switzerland), 8(7), 1-17.

Grant, M. J., \& Booth, A. (2009). A typology of reviews: an analysis of 14 review types and associated methodologies. Health Information \& Libraries Journal, 26(2), 91-108.

Hasan, M. M., Jiang, D., Ullah, A. M. M. S. ve Noor-E-Alam, M. (2020). Resilient supplier selection in logistics 4.0 with heterogeneous information. Expert Systems with Applications, 139, 1-24.

Hilpert, H., Kranz, J. ve Schumann, M. (2013). Leveraging green is in logistics: Developing an artifact for greenhouse gas emission tracking. Business and Information Systems Engineering, 5(5), 315-325.

Hsiao, W. H. ve Chang, T. S. (2019). Exploring the opportunity of digital voice assistants in the logistics and transportation industry. Journal of Enterprise Information Management, 32(6), 1034-1050.

Jabbar, S., Khan, M., Silva, B. N. ve Han, K. (2018). A REST-based industrial web of things' framework for smart warehousing. Journal of Supercomputing, 74(9), 4419-4433.

Karagöz, B. ve Bumin Doyduk, H. B. (2020). Lojistik 4.0 uygulamaları ve lojistik firmalarının bakış açısı. İnsan ve Insan Dergisi, 7(23), 37-51.

Kodym, O., Kubáč, L. ve Kavka, L. (2020). Risks associated with Logistics 4.0 and their minimization using Blockchain. Open Engineering, 10(1), 74-85.

Krykavskyy, Y., Pokhylchenko, O. ve Hayvanovych, N. (2019). Supply chain development drivers in industry 4.0 in Ukrainian enterprises. Oeconomia Copernicana, 10(2), 273-290.

La Scalia, G., Aiello, G., Miceli, A., Nasca, A., Alfonzo, A. ve Settanni, L. (2016). Effect of Vibration on the Quality of Strawberry Fruits Caused by Simulated Transport. Journal of Food Process Engineering, 39(2), 140-156.

La Scalia, G., Nasca, A., Corona, O., Settanni, L. ve Micale, R. (2017). An Innovative Shelf Life Model Based on Smart Logistic Unit for an Efficient Management of the Perishable Food Supply Chain. Journal of Food Process Engineering, 40(1), 1-13.

Lee, C. K. M., Lin, B., Ng, K. K. H., Lv, Y. ve Tai, W. C. (2019). Smart robotic mobile fulfillment system with dynamic conflict-free strategies considering cyber-physical integration. Advanced Engineering Informatics, 42, $1-12$. 
Lee, C. K. M., Lv, Y., Ng, K. K. H., Ho, W., ve Choy, K. L. (2018). Design and application of internet of things-based warehouse management system for smart logistics. International Journal of Production Research, 56(8), 27532768.

Lee, S., Kang, Y. ve Prabhu, V. V. (2016). Smart logistics: distributed control of green crowdsourced parcel services. International Journal of Production Research, 54(23), 6956-6968.

Levina, E. ve Razumova, Y. (2019). Digitalization of the transport and logistics market: integration of information systems. Russian experience in introducing digital technologies in the organization of logistics processes. Revista Amazonía Investiga, 8(22), 269-279.

Liao, Y., Deschamps, F., Loures, E. de F. R. ve Ramos, L. F. P. (2017). Past, present and future of Industry 4.0 - a systematic literature review and research agenda proposal. International Journal of Production Research, 55(12), 3609-3629.

Lin, N., Shi, Y., Zhang, T. ve Wang, X. (2019). An Effective Order-Aware Hybrid Genetic Algorithm for Capacitated Vehicle Routing Problems in Internet of Things. IEEE Access, 7, 86102-86114.

Luo, C. ve Fu, Q. (2017). Smart logistics monitoring system for hazardous chemicals based on wireless sensor technology. Chemical Engineering Transactions, 62, 787-792.

La Scalia, G., Micale, R., Certa, A., ve Enea, M. (2015). Ranking of shelf life models based on smart logistic unit using the ELECTRE III method. International Journal of Applied Engineering Research, 10(17), 38009-38015.

Ma, X., Wang, J., Bai, Q. ve Wang, S. (2020). Optimization of a three-echelon cold chain considering freshnesskeeping efforts under cap-and-trade regulation in Industry 4.0. International Journal of Production Economics, 220,1-16.

Müller, J. M. ve Voigt, K. I. (2018). The Impact of Industry 4.0 on Supply Chains in Engineer-to-Order Industries - An Exploratory Case Study. IFAC-PapersOnLine, 51(11), 122-127.

Özdemir, A. ve Özgüner, M. (2018). Endüstri 4.0 ve lojistik sektörüne etkileri: lojistik 4.0. Işsletme ve İktisat Çalışmaları Dergisi, 6(4), 39-47.

Öztemel, E. ve Gürsev, S. (2018). Lojistik yönetimi üzerinde endüstri 4.0 etkileri ve stratejik planlaması. Marmara Fen Bilimleri Dergisi, 2, 145-154.

Pan, T. (2012). Value chain analysis method of smart logistics using fuzzy theory. Information Technology Journal, $11(4), 441-445$.

Petersen, K., Feldt, R., Mujitaba, S. ve Mattsson, M. (2008). Systematic mapping studies in software engineering. Proceedings of the 12th International Conference on Evaluation and Assessment in Software Engineering, 6877.

Poenicke, O., Groneberg, M. ve Richter, K. (2019). Method for the planning of IoT use cases in Smart Logistics Zones. IFAC-PapersOnLine, 52(13), 2449-2454.

Rakyta, M., Fusko, M., Herčko, J., Závodská, L. ve Zrnić, N. (2016). Proactive approach to smart maintenance and logistics as a auxiliary and service processes in a company. Journal of Applied Engineering Science, 14(4), 433-442.

Ranieri, L., Digiesi, S., Silvestri, B. ve Roccotelli, M. (2018). A review of last mile logistics innovations in an externalities cost reduction vision. Sustainability (Switzerland), 10(3), 1-18.

Samir, T., Abdelsamad, C., Aziz, S. ve Jamila, E. (2019). Big data research on the green internet of things in new smart-logistics. International Journal of Innovative Technology and Exploring Engineering, 8(9 Special Issue 2), 534-537.

Sarkar, B., Guchhait, R., Sarkar, M. ve Cárdenas-Barrón, L. E. (2019). How does an industry manage the optimum cash flow within a smart production system with the carbon footprint and carbon emission under logistics framework? International Journal of Production Economics, 213(March), 243-257.

Schumann, M., Leye, S. ve Popov, A. (2015). Virtual Reality Models and Digital Engineering Solutions for Technology Transfer. Applied Computer Systems, 17(1), 27-33.

Sciortino, R., Micale, R., Enea, M. ve La Scalia, G. (2016). A webGIS-based system for real time shelf life prediction. Computers and Electronics in Agriculture, 127, 451-459.

Sicari, S., Rizzardi, A. ve Coen-Porisini, A. (2019). Smart transport and logistics: A Node-RED implementation. Internet Technology Letters, 2(2), e88.

Sivamani, S., Kwak, K. ve Cho, Y. (2014). A study on intelligent user-centric logistics service model using ontology. 
Journal of Applied Mathematics, 2014.

Stachowiak, A., Adamczak, M., Hadas, L., Domanski, R., ve Cyplik, P. (2019). Knowledge Absorption Capacity as a Factor for Increasing Logistics 4.0 Maturity. Applied Sciences, (9), 1-11.

Strandhagen, J. O., Vallandingham, L. R., Fragapane, G., Strandhagen, J. W., Stangeland, A. B. H. ve Sharma, N. (2017). Logistics 4.0 and emerging sustainable business models. Advances in Manufacturing, 5(4), 359-369.

Su, Y. ve Fan, Q. M. (2020). The Green Vehicle Routing Problem from a Smart Logistics Perspective. IEEE Access, $8(2), 839-846$.

Sutawijaya, A. H., ve Nawangsari, L. C. (2020). What is the impact of industry 4.0 to green supply chain? Journal of Environmental Treatment Techniques, 8(1), 207-213.

Tatham, P., Stadler, F., Murray, A. ve Shaban, R. Z. (2017). Flying maggots: a smart logistic solution to an enduring medical challenge. Journal of Humanitarian Logistics and Supply Chain Management, 7(2), 172-193.

Teucke, M., Broda, E., Börold, A., ve Freitag, M. (2018). Using sensor-based quality data in automotive supply chains. Machines, 6(4), 1-22.

Trab, S., Bajic, E., Zouinkhi, A., Thomas, A., Abdelkrim, M. N., Chekir, H. ve Ltaief, R. H. (2017). A communicating object's approach for smart logistics and safety issues in warehouses. Concurrent Engineering Research and Applications, 25(1), 53-67.

Trappey, A. J. C., Trappey, C. V., Fan, C. Y., Hsu, A. P. T., Li, X. K. ve Lee, I. J. Y. (2017). IoT patent roadmap for smart logistic service provision in the context of Industry 4.0. Journal of the Chinese Institute of Engineers, Transactions of the Chinese Institute of Engineers,Series A/Chung-Kuo Kung Ch'eng Hsuch K'an, 40(7), 593602.

Vasin, S., Gamidullaeva, L., Shkarupeta, E., Palatkin, I. ve Vasina, T. (2018). Emerging trends and opportunities for industry 4.0 development in Russia. European Research Studies Journal, 21(3), 63-76.

Webster, J. ve Watson, R. T. (2002). Analyzing the past to prepare for the future: writing a literature review. MIS Quarterly, 26(2), 13-23.

Wen, J., He, L. ve Zhu, F. (2018). Swarm Robotics Control and Communications: Imminent Challenges for Next Generation Smart Logistics. IEEE Communications Magazine, 56(7), 102-107.

Wienhofen, L. W., Mathisen, B. M., \& Roman, D. (2015). Empirical big data research: a systematic literature mapping. arXiv preprint arXiv:1509.03045.

Winkelhaus, S. ve Grosse, E. H. (2020). Logistics 4.0: a systematic review towards a new logistics system. International Journal of Production Research, 58(1), 18-43.

Xie, G. (2018). Smart logistics management of hazardous chemicals based on internet of things. Chemical Engineering Transactions, 67, 85-90.

Xu, J., Jiao, Y. ve Yuan, Y. (2013). Constructing and the related key techniques for the Smart Logistics Information Platform of Yiwu Port. Journal of Theoretical and Applied Information Technology, 51(3), 482-488.

Yavas, V. ve Ozkan-Ozen, Y. D. (2020). Logistics centers in the new industrial era: A proposed framework for logistics center 4.0. Transportation Research Part E: Logistics and Transportation Review, 135

Yılmaz, Ü. ve Duman, B. (2019). Lojistik 4.0 Kavramına Genel Bir Bakış: Geçmişten Bugüne Gelişim ve Değişimi. Bilecik Şeyh Edebali Üniversitesi Sosyal Bilimler Enstitüsü Dergisi, 186-200.

Yu, Y. W., Jung, H. ve Bae, H. (2015). Integrated GIS-based logistics process monitoring framework with convenient work processing environment for smart logistics. ETRI Journal, 37(2), 306-316.

Zhang, A., Venkatesh, V. G., Liu, Y., Wan, M., Qu, T. ve Huisingh, D. (2019). Barriers to smart waste management for a circular economy in China. Journal of Cleaner Production, 24.

Zhang, N. (2018). Smart logistics path for cyber-physical systems with internet of things. IEEE Access, 6, 7080870819.

Zhou, W., Piramuthu, S., Chu, F. ve Chu, C. (2017). RFID-enabled flexible warehousing. Decision Support Systems, 98, 99-112. 


\title{
Extended Summary
}

\section{Digital Transformation of Logistics Management: A Systematic Literature Mapping on Smart Logistics}

\begin{abstract}
"Smart" is one of the most popular words in recent years. There is an intense smartness initiative on many issues such as smartphones, smart factories, smart logistics, smart homes, smart cities, smart roads. Logistics management also took its share from this smartness trend. Despite the fact that the use of smart systems in logistics management started to be suggested with the lacking of traditional logistics, Germany's new industrial breakthrough, which emerged at the Hannover fair in 2011, has gained popularity with the concept of "industry 4.0" (Krykavskyy, Pokhylchenko, and Pratikovych, 2019: 275; Pan, 2012: 441).

The use of digital transformation-based technologies in logistics is called "smart logistics" or "logistics 4.0" (Müller and Voigt, 2018: 122). In this study, the use of the term "smart logistics" was preferred. When we evaluate the studies in the field of smart logistics, first of all, the concepts of smart logistics "smart logistics" and "logistics 4.0" are used interchangeably, but in many studies, it is conceptual confusion that only one of these concepts is selected and the synonym between these two concepts is not specified. Therefore, the concept of "Smart Logistics" was used in this study.
\end{abstract}

The studies in this area have progressed in a more technology-oriented framework rather than being placed around a framework such as smart logistics. This led to reduced attention from the desired integration goal and the lack of a integrated smart logistics framework. When we evaluate the studies carried out for "smart logistics", it was observed that it was generally limited. Although the number of smart logistics studies has increased in recent years, the systematic literature review regarding the evaluation of these studies is limited (Winkelhaus \& Grosse, 2020). This study aims to carry out a more integrated literature review and make an important contribution to the literature by evaluating concepts both in smart logistics and logistics 4.0.

In this study, systematic mapping method was used. Systematic mapping method helps to reveal the deficiencies in that area by mapping the studies in the study area (Petersen, Feldt, Mujitaba, and Mattsson, 2008). The main purpose of the study is to reveal a review by examining the studies that involve making logistics processes defined as "smart logistics" and "logistics 4.0" more efficient and more sustainable by using information and communication technologies.

"Web of Scince" and "Scopus", in which the most respected scientific publications are accepted, were chosen as the database. Also, "Dergipark" database has been included to evaluate Turkish publications. There are studies in the literature about the digitalization of logistics processes or the use of information technologies in logistics. However, as the studies involving the concept of smart logistics are taken into consideration, as keywords; the words "smart logistics", "smart logistic", "logistics 4.0" and "logistic 4.0" were scanned. In the search made in Dergipark, the words "smart logistics" and "logistics 4.0", which are the Turkish equivalent of these words, were scanned. The screening was carried out in March 2020.

The findings were evaluated within the framework of certain preliminary criteria. First of all, sources such as papers, books, book chapters, technical reports and theses have been eliminated and only articles that have passed the referee process are included. As the publication language, studies written in English for Web of Science and Scopus and in Turkish for Dergipark are taken into consideration. It has been paid attention to include the keywords that are determined in the title, abstract or one of the keywords. 
As a result of the screening, 148 publications were selected in the Web of Science database and 50 of these publications constitute articles. 245 publications have been selected in Scopus database and 81 of these publications are articles. In Dergipark, 13 articles were identified. 144 articles were obtained in total.

The results were reviewed by filtering method on a database basis in order to identify the most relevant articles for the purpose. It was paid attention not to include repetitive and irrelevant publications in the filtering method. First, the Web of Science database was evaluated and studies that were not related to the subject were removed and reduced to 41 articles. Secondly, Scopus database has been evaluated, the number has been reduced to 45 by publishing the same publications as Web of Science, and then it has been published as 19 articles by removing irrelevant publications. In the review made in the database of Dergipark, the article was reduced to 7 . Totaly, 67 articles are selected.

Even though the studies on smart logistics are based on 2008, it is seen that the researchers turned to this field especially after 2015. After 2015, there is a steady increase in the number of publications and reached its peak with 20 publications in 2019 . When we evaluate the number of citations of articles in the field of smart logistics, the most citation was made in 2017. Also, "Sustainability" and "Applied Science" are the most contributing journals with three publications in this field.

In studies by types, there are 14 review and survey studies, 13 practical solution studies, 20 discussion studies and 20 theoretical solution studies. In studies by topics, there are 29 digital transformation, 7 transportation, 7 warehouse management, 7 inventory management, 2 risk management, 9 information communication technologies, 5 green logistics and 1 logistics center.

The application of digital transformation technologies will lead to changes in companies in many areas such as processes, human resources, organization and culture. At the core of the work is the integrated infrastructure, expertise, data and data analytics. Creating a digital culture in companies is a long-term business. With these technologies, company leanness and agility will increase. When this process is approached strategically, it should be kept in mind that it will take 4-5 years and will require significant investment financing. Therefore, the digital transformation strategy and road map should be determined by first determining the level of digital maturity. The sponsor of this project should be one of the most senior managers of the company. 
Optimum Journal of Economics and Management Sciences, Vo1. 7, No. 2- http://dergipark.org.trloptimum Karlı and Tanyaş - Digital Transformation of Logistics Management: A Systematic Literature Mapping on smart Logistics 